\title{
ANIMAL COMBATE: \\ UM NOVO INSTRUMENTO PEDAgógico \\ PARA O ENSINO DE CIÊNCIAS E BIOLOGIA
}

\begin{tabular}{c}
\hline ANIMAL COMBAT: \\
A NEW PEDAGOGICAL INSTRUMENT FOR \\
SCIENCE AND BIOLOGY TEACHING \\
\hline ANIMAL COMBATE: \\
UN NUEVO INSTRUMENTO PEDAGÓGICO \\
PARA LA ENSEÑANZA DE CIENCIAS Y BIOLOGÍA \\
\hline
\end{tabular}

Leandra de Amorim da Silva

Angélica Massarolli²

Alessandra Regina Butnari ${ }^{3}$

\begin{abstract}
RESUMO: Por vezes os alunos se sentem desmotivados com o modelo de aula tradicional e os jogos didáticos surgem com o intuito de tornar as aulas mais dinâmicas, principalmente em conteúdos complexos, como os de biologia, estimulando o aprendizado. Assim, o trabalho teve como objetivo avaliar a aplicabilidade do jogo "Animal Combate", como instrumento pedagógico e motivacional para o ensino de temas de biologia e verificar o nível de conhecimento dos alunos após a aplicação do jogo. O jogo foi aplicado em turmas do ensino médio, em que os alunos responderam dois questionários avaliativos, sendo um pré e um pós-atividade didática, com perguntas abertas e de múltipla escolha, sendo avaliados apenas os acertos nas alternativas. O jogo proposto, foi adequado para a série/ano na qual foi aplicado, caracterizando-se como uma ferramenta complementar de ensino e aprendizagem, demostrando um aumento nos acertos das respostas, mostrando-se eficaz como instrumento motivador da aprendizagem do conteúdo de Biologia.
\end{abstract}

PALAVRAS-ChaVE: Atividade-didática. Jogos didáticos. Ensino de ciências e biologia.

ABSTRACT: The students sometimes feel unmotivated by the traditional classroom model, and educational games are designed to make classes more dynamic, especially complex content like biology, stimulating learning. The aim of this study was to evaluate the applicability of the "Animal Combate" game as a pedagogical and motivational tool for to teach biology's subjects and to verify their level of knowledge about these subjects. The game was applied in a public school in three high school classes, where the students answered two evaluative questionnaires, being a pre and post educational activity, with open and multiple choice questions, being evaluated just the correct answers in the alternatives. The proposed game, was adequate for the series in which it was applied, characterizing itself as a complementary teaching and learning tool, demonstrating an increase in the right answers, proving to be effective as a motivational tool for learning the Content of Biology.

KEYWORDS: Educational activity. Educational games. Science and biology teaching.

RESUMÉN: A veces los alumnos se sienten desmotivados con el modelo de clase tradicional, y los juegos didácticos surgen con el propósito de hacer las clases más dinámicas, principalmente en contenidos complejos,

${ }^{1}$ Submetido em: 05/09/2017 - Aceito em: 26/09/2017 - Publicado em: 14/02/2018.

(C) Rev. Educ. Perspec.

\begin{tabular}{l|l} 
Viçosa, $M G$ & v.8
\end{tabular}

n.3

p.496-517

set./dez.2017

eISSN 2178-8359 
como los de biología, estimulando el aprendizaje. Así, el trabajo tuvo como objetivo evaluar la aplicabilidad del juego "Animal Combate", como instrumento pedagógico y motivacional para la enseñanza de temas de biología y verificar el nivel de conocimiento de los mismos. El juego fue aplicado en clases de enseñanza media, donde los alumnos respondieron dos cuestionarios de evaluación, siendo un pre y un post-actividad didáctica, con preguntas abiertas y de múltiple elección, siendo evaluados apenas los aciertos en las alternativas. El juego propuesto, fue adecuado para la serie en la que fue aplicado, caracterizándose como una herramienta complementaria de enseñanza y aprendizaje, demostrando un aumento en los aciertos de las respuestas, mostrándose eficaz como instrumento motivador del aprendizaje el contenido de Biología.

PALABRAS CLAVE: Actividad-didáctica. Juegos didácticos. Enseñanza de ciencias y biología.

\section{INTRODUÇÃO}

Desde a década de 1950, há uma preocupação com o ensino de Ciências e Biologia e uma busca por métodos que auxiliassem e melhorassem o ensino nestas áreas (DELIZOICOV; ANGOTTI, 1994). Deste modo, segundo Gagné (1971), os materiais didáticos surgiram como uma ferramenta de ensino para os professores e como estímulo ao aprendizado para os alunos.

Atualmente, muitas escolas se encontram em defasagem devido à falta de recursos financeiros e didáticos, o que torna as aulas repetitivas e cansativas sem algo que estimule os alunos a querer aprender (PAJOLA et al., 2009). Para Jann e Leite (2010), uma alternativa é o uso dos jogos didáticos, que podem auxiliar o professor no processo de ensino e aprendizagem, uma vez que se configuram como recursos de grande aceitação por parte dos alunos envolvidos e são de baixo custo, em comparação com outras tecnologias existentes em escolas com boa infraestrutura (SILVA; MORAIS, 2011; AMORIM, 2013).

No entanto, a maioria das escolas não possui essa boa infraestrutura para ajudar o professor e, apesar de jogos didáticos serem uma ferramenta conhecida na área acadêmica, na prática é pouco usada pelos docentes em suas aulas, muitas vezes devido à falta de tempo ou mesmo de materiais para elaborar os jogos (CAMPOS; BORTOLOTO; FELICIO, 2003; PINTO, 2009; NEVES; SOUSA; ARRAIS, 2009), tornando por vezes as aulas "chatas" e "monótonas", em que os alunos são apenas ouvintes de informações que já vem prontas (JORGE et al., 2009).

Segundo com Miranda (2001), os jogos didáticos atuam no desenvolvimento de aspectos cognitivos, afetivos, sociais e criativos, o que estimula os alunos a terem um maior rendimento. Além disso, estes se sentem mais livres para argumentar, criticar e discutir, ou até mesmo questionar algo, o que não ocorre com frequência durante as aulas tradicionais (JORGE et al., 2009). Tendo em vista que ao longo do ensino médio, muitos conceitos vão sendo esquecidos pelos alunos, principalmente os de biologia, que são considerados conteúdos extensos, complexos e difíceis de serem ministrados (CAMPOS; BORTOLOTO;

\begin{tabular}{l|c|c|c|c|c|c} 
() Rev. Educ. Perspec. & Viçosa, $M G$ & v.8 & n.3 & p.496-517 & set./dez.2017 & eISSN 2178-8359 \\
\hline
\end{tabular}




\section{RELATO DE EXPERIÊNCIA}

DOI: 10.22294/eduper/ppge/ufv.v8i3.897

FELICIO, 2003), a aplicação de jogos didáticos, voltados para a disciplina, pode ajudar na revisão, fixação e no reforço desses conteúdos (CASAS et al., 2010).

Os alunos consideram gravar nomes, estruturas e vários conceitos cansativos e, por isso, não gostam da matéria de Biologia. E, de acordo com Pinto (2009, p. 16), "o uso de jogos didáticos em ensino de ciências é uma estratégia eficaz, pois cria uma atmosfera de motivação que permite ao aluno participar ativamente do processo de ensino-aprendizagem".

Dentre os vários conteúdos que abrangem as ciências, o que mais desperta a curiosidade nos alunos são os animais, assim como o ambiente, o estudo de suas características como o habitat, a reprodução, a locomoção e a compreensão do processo do ciclo vital dos mesmos (ASSIS et al., 2011). A sugestão de tornar as aulas mais dinâmicas para os conteúdos de zoologia e ecologia nas aulas de Biologia, a partir da utilização de jogos didáticos, permite aos alunos assimilarem os conteúdos trabalhados no jogo com maior facilidade, de modo que compreendam melhor a diversidade de espécies existentes e as características e particularidades dessas (ASSIS et al., 2011), havendo uma necessidade de se buscar por novos jogos que envolvam temas estudados nas aulas de Biologia.

Sendo assim, foi desenvolvido o jogo "Animal Combate" dentro do subprojeto de extensão "Os bichos ensinam: abordagens zoológicas na escola" financiado pela Coordenação de Aperfeiçoamento de Pessoal de Nível Superior (CAPES) dentro do Programa Novos Talentos, que pode ser utilizado como promotor do ensino-aprendizagem em práticas escolares, aproximando os alunos do conhecimento científico, permitindo uma convivência social. O jogo foi desenvolvido para auxiliar o professor no ensino de conteúdos de zoologia e ecologia, conteúdos estes muito extensos e, por vezes, de difícil assimilação.

Assim, o presente trabalho teve como objetivo avaliar a aplicabilidade do jogo "Animal Combate" como instrumento pedagógico e motivacional para o ensino de temas de biologia em turmas do último ano do ensino médio e verificar o nível de conhecimento dos alunos sobre a temática proposta em uma escola da rede pública de ensino.

\section{MATERIAL E MÉTODOS}

\section{O Jogo: Animal Combate}

O jogo foi desenvolvido por uma equipe de professores e alunos do curso de Licenciatura e Bacharelado em Ciências Biológicas da Universidade do Estado de Mato Grosso (UNEMAT) campus de Tangará da Serra, Mato Grosso. É um jogo de cartas, que comporta de dois a cinco participantes disputando 50 cartas, cujo objetivo é um dos jogadores ficar com o maior número de cartas possíveis do baralho para ganhar a rodada ${ }^{\mathrm{i}}$.

\begin{tabular}{l|c|c|c|c|c|c} 
(C) Rev. Educ. Perspec. & Viçosa, $M G$ & v.8 & n.3 & p.496-517 & set./dez.2017 & eISSN 2178-8359 \\
\hline
\end{tabular}


As cartas contêm informações sobre os cinco grupos de animais vertebrados existentes (Figura 1), peixes, anfíbios, répteis, aves e mamíferos. Para cada um desses grupos, são apresentados 10 animais da fauna brasileira e estrangeira. As cartas possuem informações básicas na parte superior, como o nome científico e popular da espécie, a qual família pertence e sua alimentação, além da imagem do animal, e, na parte inferior, as informações que são utilizadas no jogo para disputa (tamanho e peso do animal, tempo médio de vida, número de filhotes (Prole), classificação da União internacional de conservação dos recursos naturais (IUCN) (Figura 2) e táticas de guerra (Figura 3) que o animal possui.

O jogo possui uma carta extra, que serve para o jogador consultar qual a tática de guerra que sua carta em jogo apresenta, sendo dez as táticas de guerra/sobrevivência dos animais como podem ser observadas na figura 3 , sendo que o conjunto dessas características podem ou não estar presentes nos animais que são apresentados no jogo. As táticas de guerra usadas foram a Camuflagem (que é um conjunto de técnicas que permite que um animal se torne indistinguível no ambiente em que habita, ou seja, em não ser reconhecido); Veneno (são substâncias tóxicas produzidas pelo animal e que podem produzir algum tipo de enfermidade para o outro indivíduo); Tanatose (é a capacidade que alguns animais têm de se fingir de morto para confundir predadores); Mimetismo (é um conjunto de características que um organismo possui que faz com que ele seja confundido com outro organismo de outra espécie); Capacidade de fuga (indica meios que um organismo tem de se locomover para fugir de um predador); Odor (são cheiros repugnantes devido à produção de substâncias que provocam a percepção olfativa de outro organismo); Força (é a capacidade utilizada em disputas por alimento, fêmea, território ou mesmo para fuga); Agressividade ou Comportamento Agressivo (é utilizado normalmente para afugentar organismos de outras espécies para guardar território, alimento, procriação, etc.); Armas (são o conjunto de características de um organismo que podem ser usadas em uma batalha, como unhas, presas, secreções entre outros); Som (é o barulho produzido por um organismo que pode ser para afugentar concorrentes ou predadores).
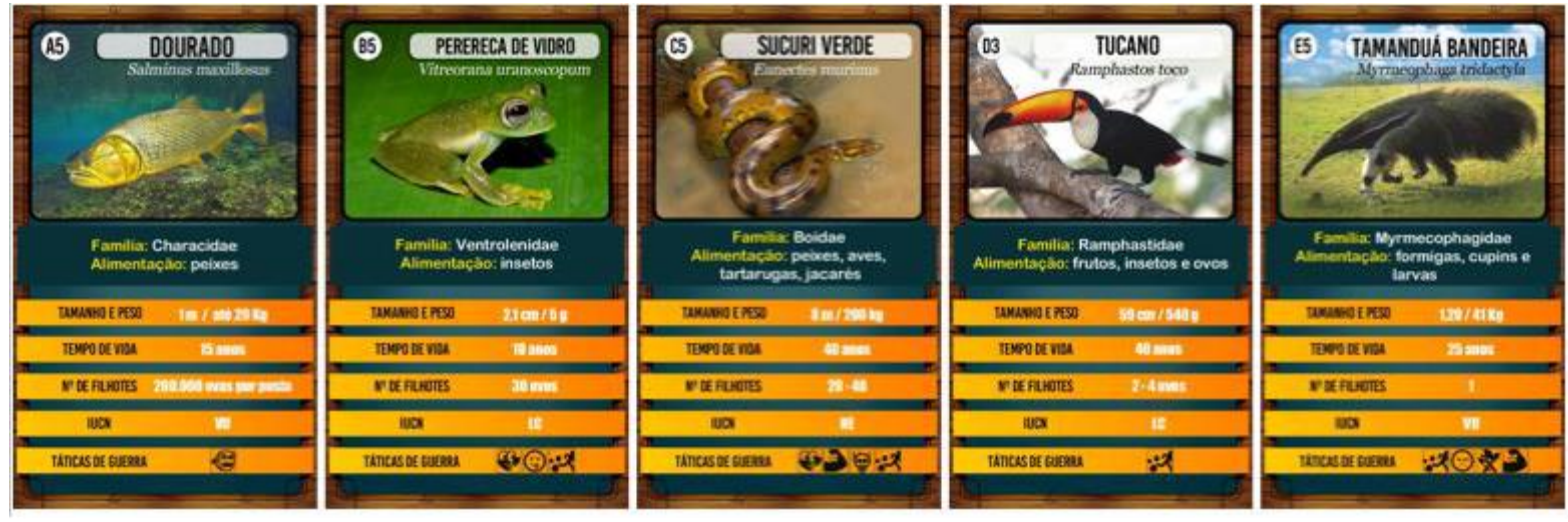

Figura 1. Cartas do jogo ilustrando os cinco grupos de vertebrados.

Fonte: As autoras.

(c) Rev. Educ. Perspec.

Viçosa, $M G$

\begin{tabular}{l|l|l|}
\hline & v. 8 & n. 3 \\
\hline
\end{tabular}

p. $496-517$

set./dez.2017

eISSN 2178-8359 


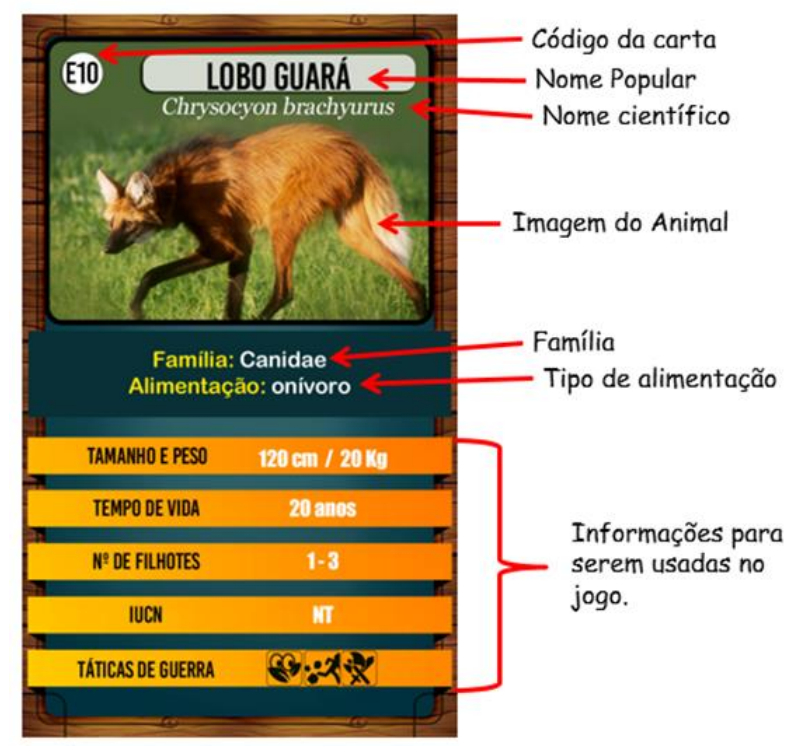

Figura 2. Exemplificando cada ponto da carta para a utilização no jogo. Fonte: As autoras.

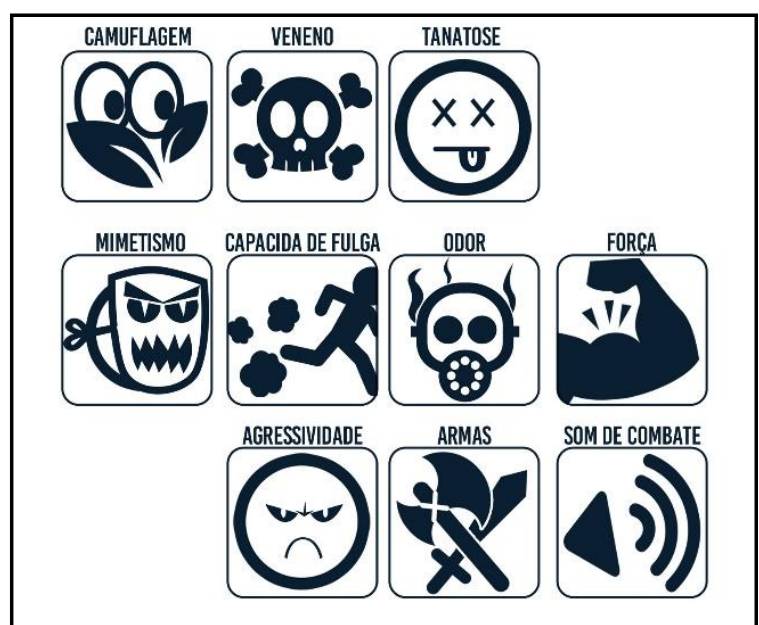

Figura 3. Carta que acompanha cada jogador e descreve as Táticas de Guerra que cada animal possui. Fonte: As autoras.

De acordo com a Lista Vermelha de Espécies Ameaçadas criada pela IUCN, as espécies foram classificadas adotando os seguintes critérios: o declínio da população, o tamanho e distribuição da população, a área de distribuição geográfica e o grau de destruição de seu habitat, sendo que nessa lista as espécies são classificadas em totalmente extinta (EX), extinta na natureza $(\mathrm{EW})$, criticamente ameaçada (CR), ameaçada (EN), vulnerável (VU), quase ameaçada (NT), pouco preocupante (LC), deficiente em dados (DD) ou não avaliada $(\mathrm{NE})$. 


\section{RELATO DE EXPERIÊNCIA}

DOI: 10.22294/eduper/ppge/ufv.v8i3.897

O jogo funciona assim: a sala é dividida em grupos de dois a cinco participantes, de acordo com o número de alunos que a turma possua, posteriormente, para iniciar o jogo, as cartas são igualmente divididas entre os participantes e cada jogador forma sua "pilha", sendo que apenas a primeira carta é vista pelo jogador. A rodada começa com a escolha de um dos itens de competição que o jogador julga que tenha valor superior, em comparação ao mesmo item da carta de seus adversários, se o valor de sua carta for maior, ele obtém todas as cartas da rodada e as coloca embaixo da sua "pilha". Do contrário, ele deve dar sua carta ao ganhador que será o próximo a jogar e escolher o item em sua carta para competir.

\section{Local de Aplicação do Jogo}

O jogo "Animal Combate" foi aplicado nos meses de novembro e dezembro de 2016, em três turmas de terceiro ano do ensino médio nos três períodos (matutino, vespertino e noturno) em uma escola da rede estadual de ensino do município de Tangará da Serra, Mato Grosso.

As três turmas eram compostas no total por 55 alunos, sendo que os que não responderam o questionário pós-atividade didática foram automaticamente excluídos da amostragem. Restando então 46 alunos, 22 meninas e 24 meninos.

As turmas do período matutino e noturno tiveram uma hora aula para a realização dos questionários e do jogo. E na turma do vespertino os alunos tiveram duas horas aula para a realização do mesmo, isto devido à disponibilidade de tempo da professora responsável em cada turma.

\section{Aplicação do Jogo e avaliação Pré e Pós-Jogo}

Para a análise da funcionalidade do jogo como um instrumento facilitador para o ensino de temas de zoologia e ecologia, primeiramente avaliou-se o conhecimento prévio dos participantes sobre os temas abordados por meio de um questionário denominado de Préatividade didática, contendo 11 questões entre discursivas e de múltipla escolha.

Em seguida, foi ministrada uma micro aula expositiva de 10 minutos sobre temas que podem ser abordados no jogo, como as táticas de guerra e outras características que os animais possuem e que são apresentadas nas cartas do jogo, tais como os critérios de classificação da IUCN quanto à conservação das espécies.

Após essa breve explanação, os alunos foram divididos em grupos, de acordo com a quantidade e preferência dos mesmos, e cada um recebeu uma caixa com o jogo contendo as 50 cartas, um manual de instruções e uma carta com táticas de guerra, posteriormente, foram esclarecidas as regras e iniciou-se o jogo.

\begin{tabular}{l|c|c|c|c|c|c} 
(c) Rev. Educ. Perspec. & Viçosa, $M G$ & v.8 & n.3 & p.496-517 & set./dez.2017 & eISSN 2178-8359 \\
\hline
\end{tabular}


Ao término das atividades, foi aplicado um segundo questionário sendo este denominado de Pós-atividade didática, contendo também 11 questões, para verificar o quanto os alunos aprenderam sobre o assunto abordado no jogo, além da opinião destes sobre a utilização do mesmo como instrumento de ensino, sendo apenas seis questões iguais a da pré-atividade, entre discursivas e de múltipla escolha.

A análise dos dados foi feita pela comparação e avaliação dos dados pré e pós-atividade didática, sendo contabilizados apenas os acertos das questões de múltipla escolha.

\section{RESULTADOS E DISCUSSÃO}

Os estudantes que participaram deste estudo apresentavam a faixa etária entre 17 e 19 anos. A maioria deles, ao responder a questão "sobre o que é zoologia", disse que é "o estudo dos animais", "matéria que fala sobre os animais" ou "algo relacionado aos animais", demonstrando conhecer o significado da palavra.

Entretanto, não escreveram nada além disso, o que mostrou que apesar dos alunos saberem o sentido do termo não conhecem a importância, o que abrange, e nem que organismos são estudados nessa área, deixando superficial o contexto da palavra em relação ao conteúdo que é tão extenso e rico como a zoologia. Segundo Amorim (2013, p. 37), “os jogos e modelos didáticos vem no intuito de direcionar e auxiliar o conteúdo de biologia, tirando essa superficialidade na qual são abordados os conceitos científicos, relacionando estes com o cotidiano do aluno".

Quando os alunos foram questionados sobre se costumam usar jogos e outras brincadeiras para aprender sobre animais em sala de aula ou fora dela, $63 \%$ dos alunos responderam que não são usados esses instrumentos para o ensino e dos que responderam positivamente, 10 alunos citaram um jogo de informática com animais, dois jogos de memória e de tabuleiro e cinco outros instrumentos pedagógicos tais como dinâmicas e seminários (Gráfico 1). 


\section{RELATO DE EXPERIÊNCIA}

DOI: 10.22294/eduper/ppge/ufv.v8i3.897

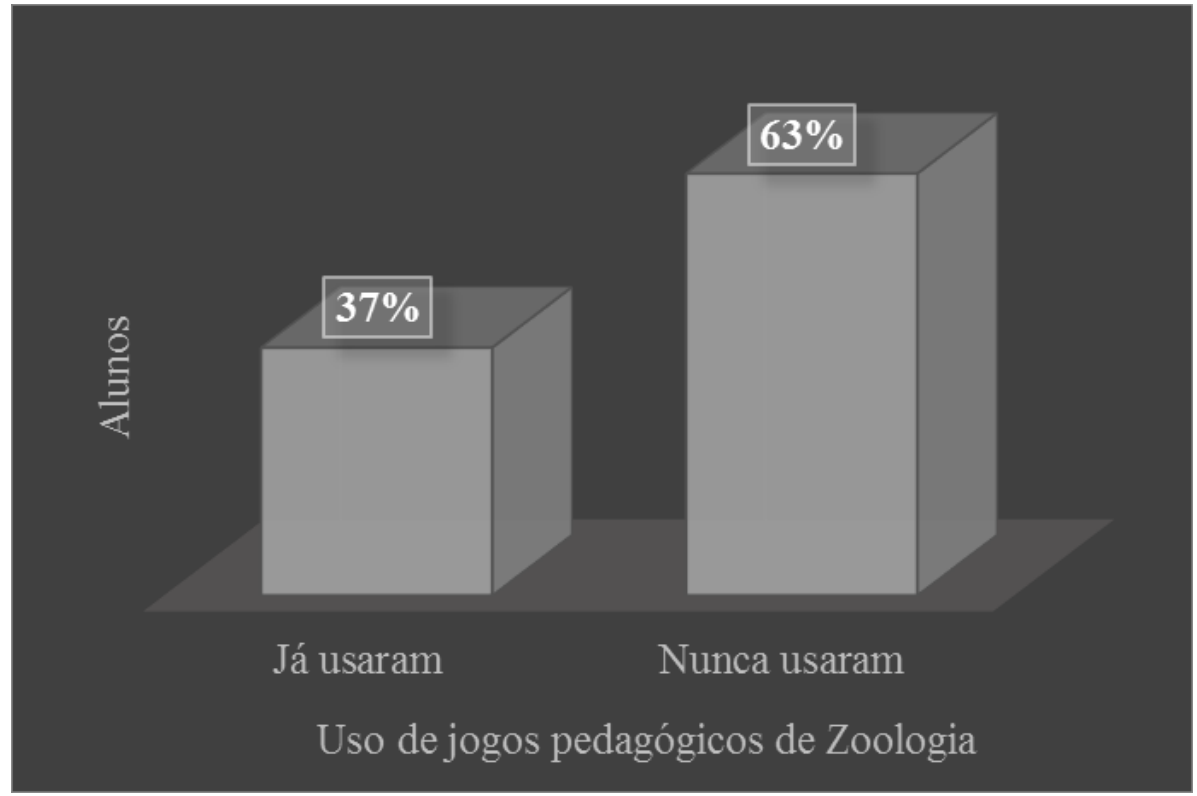

Gráfico 1. Uso de jogos pedagógicos com temas de zoologia por alunos do ensino médio de escola pública

Fonte: As autoras.

$\mathrm{Na}$ questão que teve por objetivo correlacionar a tática de sobrevivência do animal a seu conceito, tanto no questionário pré quanto no pós-atividade didática, os alunos demonstraram conhecer o conteúdo, sendo que a maior parte deles acertou as alternativas propostas, tendo um aumento do número de acertos das alternativas no questionário pós-atividade em comparação com o pré, como pode ser observado no gráfico 2.

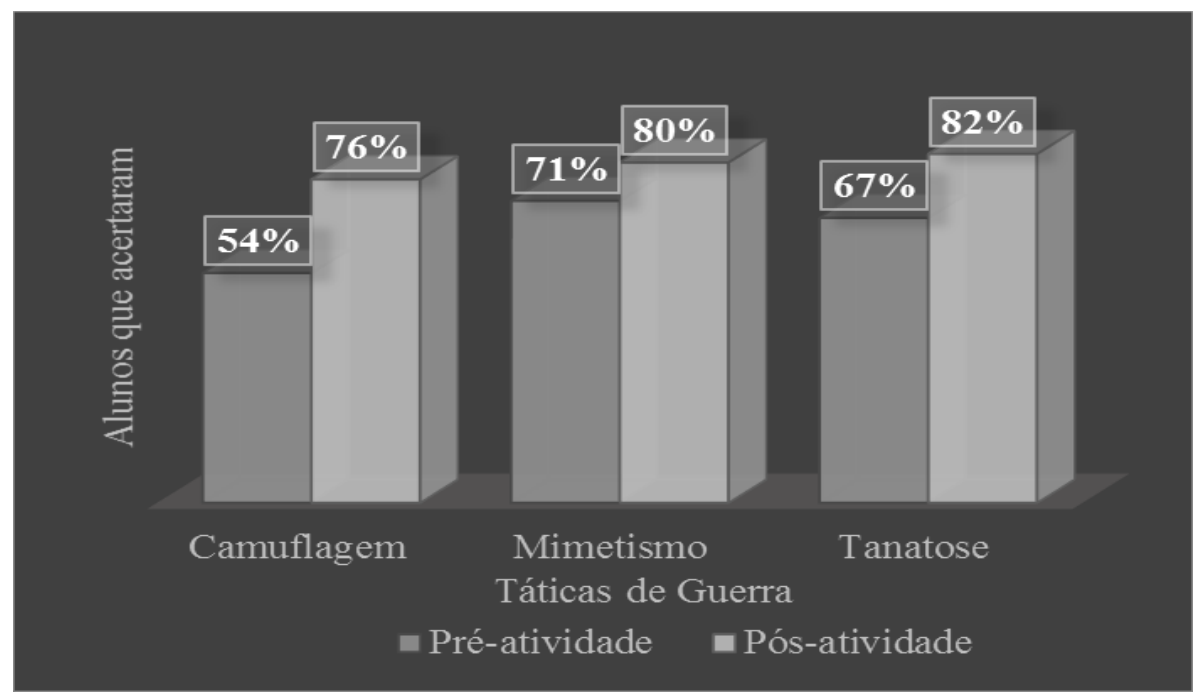

Gráfico 2. Conhecimento sobre táticas de sobrevivência dos animais antes e após o uso do jogo "Animal Combate" Fonte: As autoras. 


\section{RELATO DE EXPERIÊNCIA}

DOI: 10.22294/eduper/ppge/ufv.v8i3.897

Todavia, foi observado durante o levantamento dos dados, que os alunos se confundiram com os conceitos de mimetismo e camuflagem, por serem semelhantes, ao contrário de tanatose, em que demonstraram não conhecer o termo, no entanto, a maioria acertou. Supomos que este fato se deu porque os alunos já conheciam os outros termos em questão, e foram por exclusão, eliminando os que sabiam e o que sobrou marcaram como conceito de tanatose.

Após o jogo, os alunos que não tinham certeza ou não sabiam, passaram a conhecer o significado de tanatose, já que em conversa informal, os mesmos falaram que nunca tinham estudado ou ouvido falar deste termo como uma tática de sobrevivência animal. O que mostrou que o jogo "Animal Combate" ajudou os alunos a terem novos conhecimentos sobre o assunto, pois houve um aumento expressivo do número de acertos da questão proposta a eles como pode ser comprovado no gráfico 2 .

Quando avaliado o nível de conhecimento em relação à sistemática e filogenia abrangendo a classificação dos animais, verificou-se que os alunos não aprenderam ou esqueceram o conteúdo estudado no ano anterior, pois a maioria errou a classificação dos animais, a maneira certa de escrever e quais animais constituíam o grupo dos vertebrados citados, demonstrando possuir dificuldades em relação ao conteúdo sobre classificação animal como pode ser observado analisando-se os gráficos a seguir.

A questão quatro dizia respeito a qual grupo de vertebrados pertencia "Cecília", conhecida popularmente como cobra cega. Apenas $17 \%$ dos alunos acertaram como sendo do grupo dos anfíbios, alternativa (a), e 68\%, erroneamente, responderam a alternativa (b) répteis (Gráfico 3 ), o que nos leva a acreditar que os alunos relacionaram a cobra cega às serpentes.

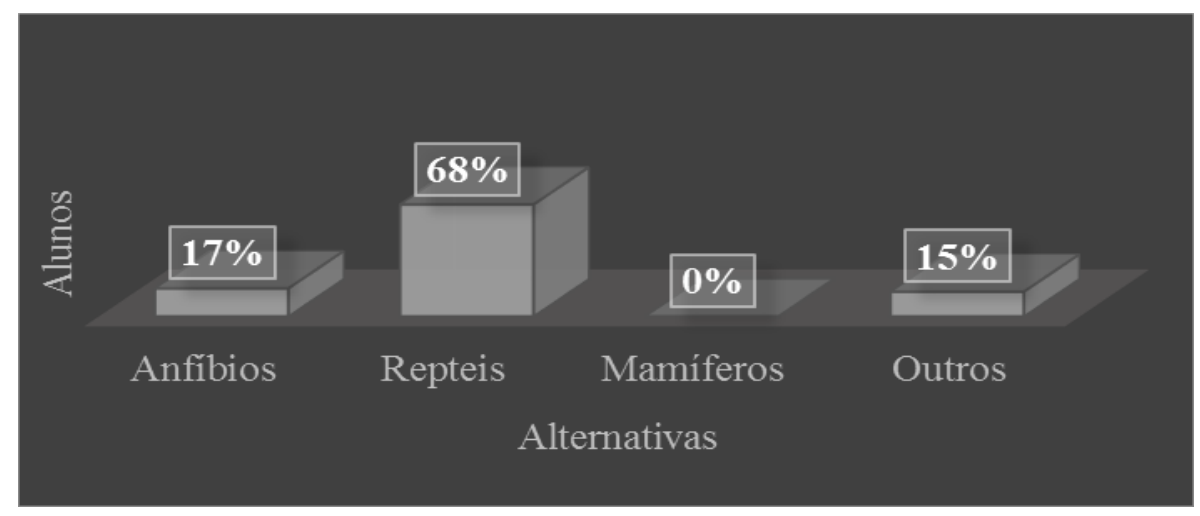

Gráfico 3. Respostas corretas de alunos do ensino médio quando indagados sobre qual grupo animal pertence a Cobra cega ou Cecília (nomes populares de Siphonoops annulatus)

Fonte: As autoras.

Já na questão sete em que os alunos precisavam "assinalar a alternativa que contém apenas animais vertebrados", apenas $15 \%$ dos alunos responderam a alternativa “(b)

\begin{tabular}{l|l|l|l} 
n.3 & p.496-517 \\
\hline
\end{tabular}




\section{RELATO DE \\ EXPERIÊNCIA}

DOI: $10.22294 /$ eduper/ppge/ufv.v8i3.897

Perereca de vidro, Sucuri verde, Javali, Cavalo marinho”, como correta (Gráfico 4), demonstrando que os estudantes têm dúvidas quando questionados em relação à classificação taxonômica de animais, pois todas as alternativas foram assinaladas. Essa constatação observada vai ao encontro dos resultados obtidos por Bastos (2013), em que 54\% dos professores entrevistados apontaram que a maior dificuldade dos alunos em conteúdo de zoologia é a classificação dos animais.

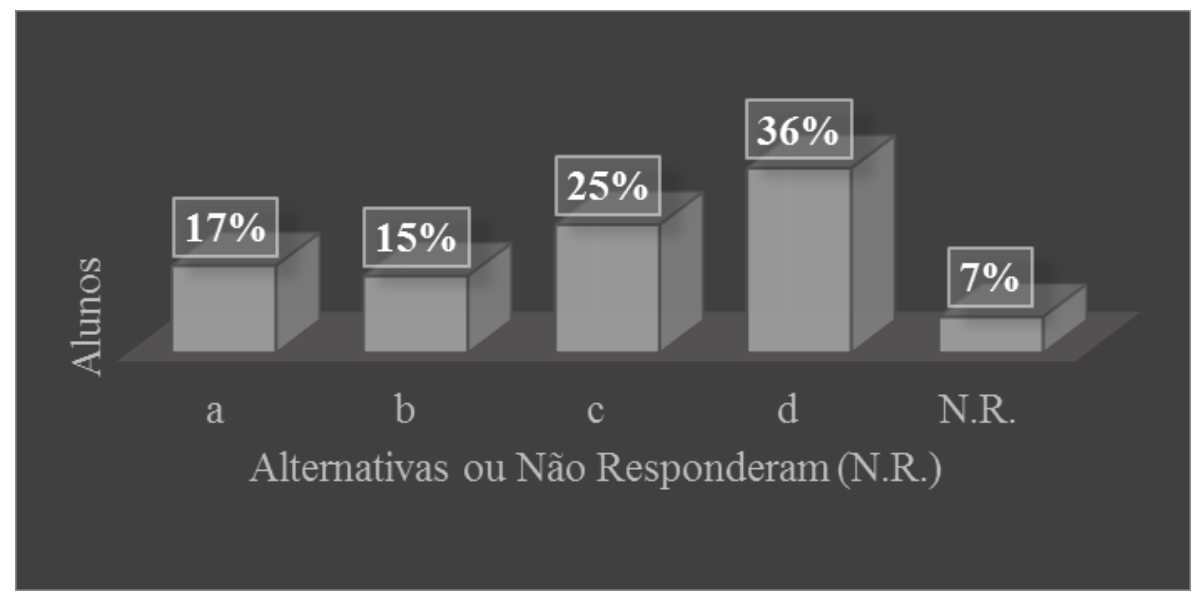

Gráfico 4. Identificação de animais vertebrados pelo nome popular por alunos do ensino médio antes do jogo Animal Combate Fonte: As autoras.

O estudo mostrou que os alunos possuem dificuldade na escrita dos nomes científicos, o que abrange o conteúdo de sistemática, pois como mostra o gráfico 5 , todas as alternativas foram assinaladas e a maioria errou a questão marcando a letra (a) como correta, sendo que a certa seria a (d), em que apenas $17 \%$ dos alunos assinalaram a maneira correta de escrever o nome científico da espécie do animal proposto na questão. Tal fato se assemelha com os resultados obtidos por Bastos (2013), em que observou que 34\% dos entrevistados em sua pesquisa teve dificuldade em relação à nomenclatura científica dos animais. 


\section{RELATO DE EXPERIÊNCIA}

DOI: 10.22294/eduper/ppge/ufv.v8i3.897

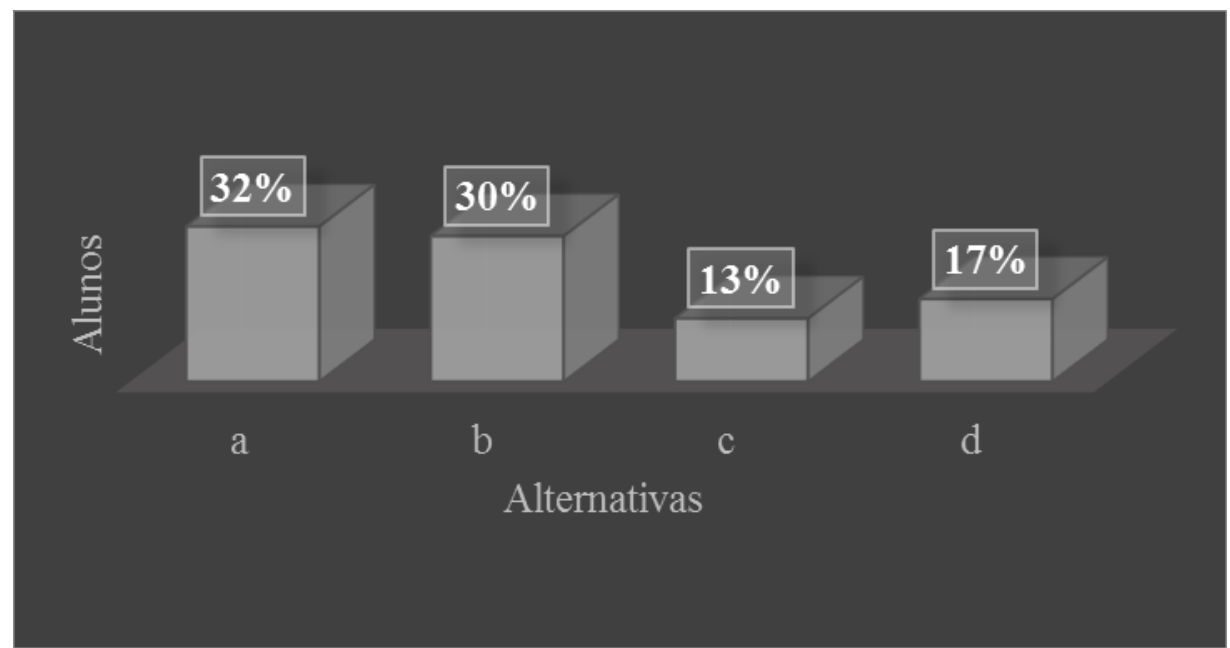

Gráfico 5. Respostas corretas dos alunos do ensino médio pós-jogo, quando questionados sobre qual o erro da frase proposta em relação a nomenclatura científica do sapo folha

Fonte: As autoras.

O que nos chamou a atenção é que a alternativa (a) trazia a informação que o sapo folha não era um anfíbio e, mesmo assim, $32 \%$ dos alunos a marcaram como correta, talvez pelo fato de não conhecerem a espécie, pensando assim ser outro animal que poderia possuir algum tipo de tática de sobrevivência, se disfarçando ou por não saberem realmente a qual grupo o sapo pertence.

Como podemos ver neste estudo, os alunos possuem dificuldades em relação à classificação dos animais em todos os níveis, sendo que os livros didáticos utilizados como instrumento pedagógico, na maioria das vezes, trazem poucas informações sobre esse tema, o que dificulta ainda mais a assimilação do conteúdo por parte dos alunos. Rodrigues et al. (2011), mostrou que os livros listados por eles abordam o conteúdo de sistemática e filogenia em poucas páginas, sendo um tema mais introdutório, sem grandes discussões sobre o assunto, deixando os alunos com várias dúvidas frente ao conteúdo, pois quando as informações não são bem claras, podem interferir na aprendizagem dos mesmos.

Tal fato acaba tornando falho o sistema utilizado pelos professores ao ensinar os conteúdos de zoologia, usando apenas o livro como auxílio, podendo interferir no aprendizado dos estudantes frente a estes conteúdos, o que é possível ser visto na questão nove (Gráfico 6), que teve por objetivo analisar se os alunos possuíam a capacidade de distinguir os representantes dos grupos dos vertebrados, em relação aos invertebrados.

A partir da análise dos questionários percebemos que os alunos possuem dificuldades ou não sabem classificar os animais em vertebrados ou invertebrados, assim como não sabem a diferença entre eles, quais são as classes de vertebrados existentes e quais animais

\begin{tabular}{l|c|c|c|c|c|c} 
() Rev. Educ. Perspec. & Viçosa, $M G$ & v.8 & n.3 & p.496-517 & set./dez.2017 & eISSN 2178-8359 \\
\hline
\end{tabular}


representam cada classe, deixando claro que o conteúdo de zoologia está sendo assimilado de forma superficial, pois dos 46 alunos que responderam os questionários, apenas $40 \%$ acertaram a alternativa correta no questionário pré-atividade didática e $43 \%$ no questionário pós-atividade, em que a questão elencava apenas uma alternativa correta contendo indivíduos dos cinco grupos que constituem os vertebrados, mostrando que não houve diferença relevante entre a pré e pós-atividade nesta questão (Gráfico 6).

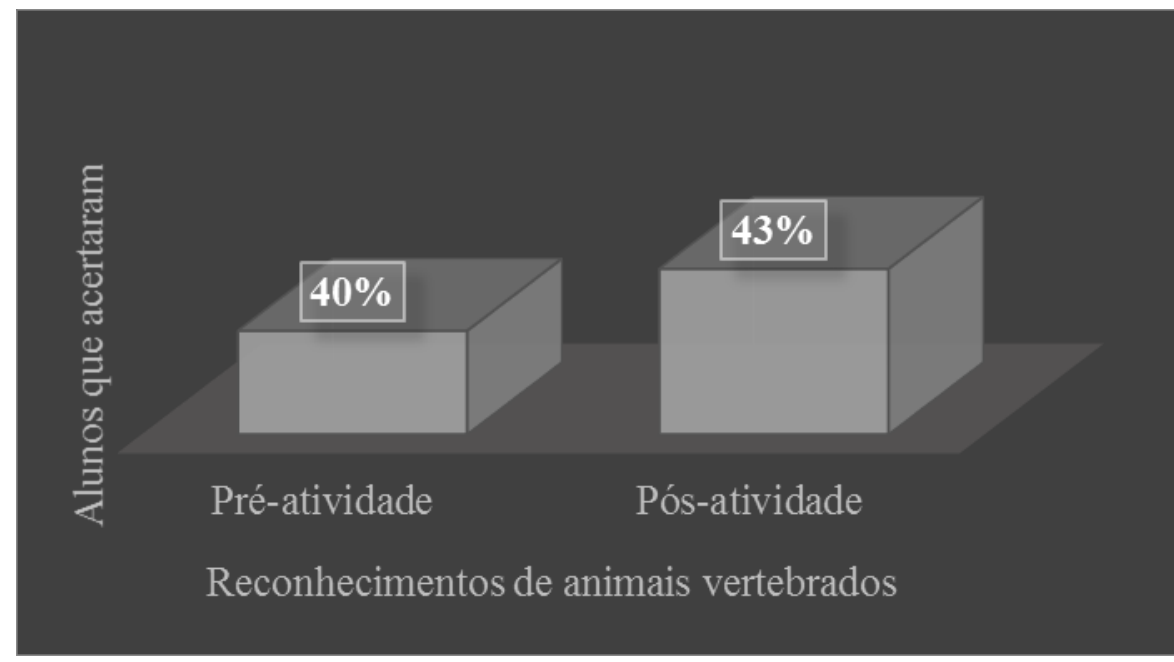

Gráfico 6. Reconhecimento de representantes dos cinco grupos de animais vertebrados por alunos do ensino médio antes e após o uso do jogo Animal Combate

Fonte: As autoras.

Outro problema enfrentado pelos professores de Ciências e Biologia é a falta de interação dos alunos com o meio ambiente, não tendo espaço e nem tempo para que, além do conhecimento sobre conservação, os alunos tenham consciência dos problemas ambientais e a necessidade da proteção aos animais (TAVARES, 2012). As respostas das questões referente a classificação dos animais de acordo com a Lista Vermelha criada pela IUCN, demonstraram que os alunos não conhecem quase nada sobre esse assunto.

Durante a aplicação dos questionários, foi possível observar que os alunos nunca tinham ouvido falar deste órgão ou dos critérios adotados por ele para classificação de risco dos animais. Devido ao pouco tempo disponível para as aulas de biologia e sem a utilização do jogo "Animal Combate", estes alunos provavelmente sairiam do ensino médio sem conhecer esse sistema que classifica os animais de acordo com o grau de risco de ser extinto na natureza.

Provavelmente isso ocorra devido ao fato dos livros didáticos em sua maioria, não trazerem textos ou informações sobre a Lista Vermelha de espécies ameaçadas, quais espécies estão em risco de extinção e nem o motivo delas estarem nessa situação, o que mostra a 
superficialidade no ensino de Biologia decorrente principalmente da falta de tempo que o professor tem no decorrer de suas aulas. Nesse contexto, Santos e Terán (2009) mencionam que o tempo restrito para abordar os conteúdos de zoologia e ecologia é um fator agravante para a falta de metodologias diferenciadas nas aulas de biologia, tornando o conteúdo maçante tanto para os alunos quanto para os professores, fazendo com que o ensino fique direcionado a apenas conteúdos considerados "mais relevantes" na construção de conhecimento dos alunos.

Entretanto, como pode ser observado no gráfico 7, houve um aumento do número de acertos das alternativas. Tendo destaque a arara azul, que deteve um aumento de acertos no questionário pós-atividade, em comparação ao questionário pré-atividade. O que permite inferir que os alunos tinham outra visão sobre a ave, pois a maioria a colocou como extinta e, na verdade, ela ainda existe, mas está em situação de vulnerabilidade. Isto se deve as informações que eles possuem e que não são atualizadas.

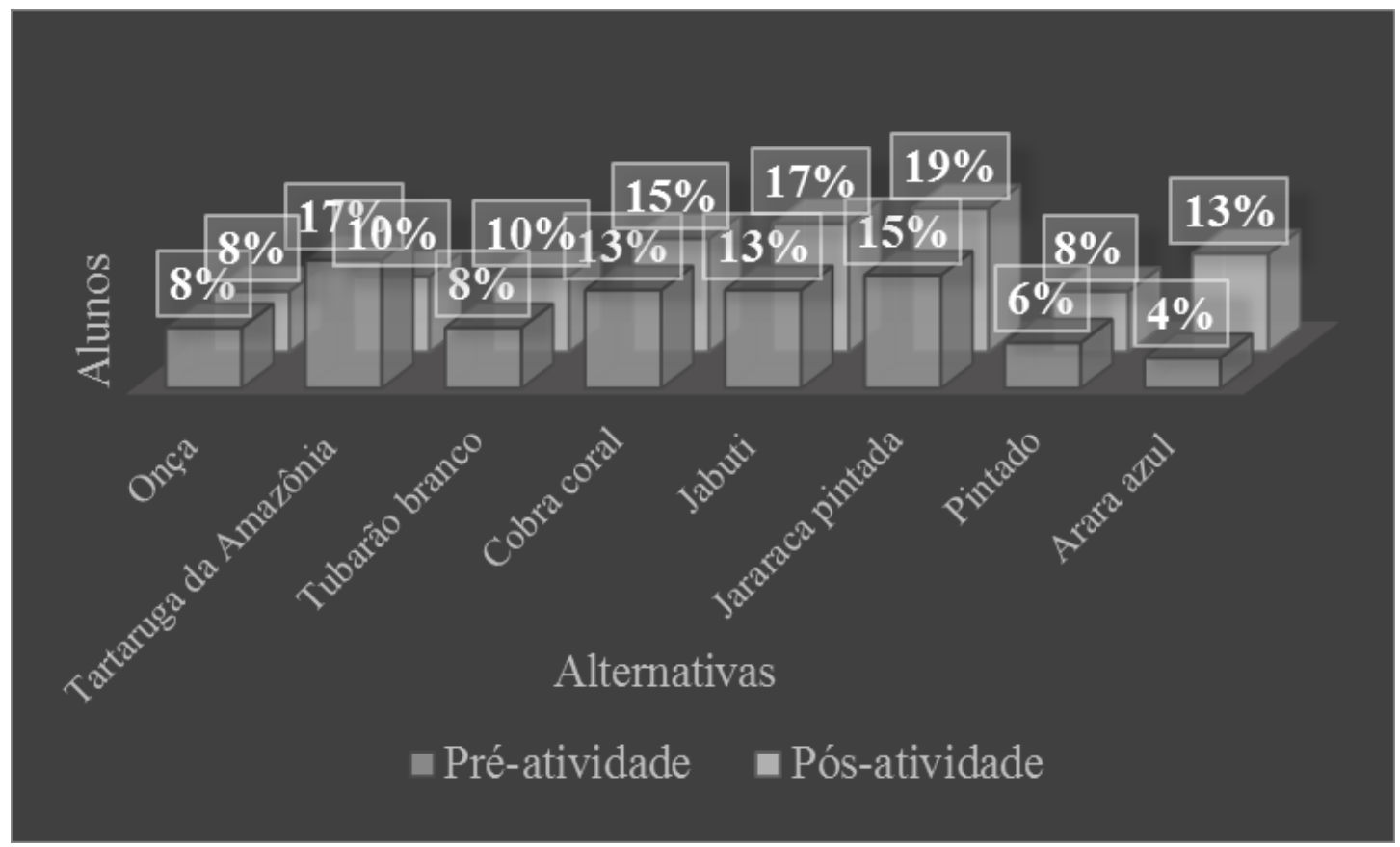

Gráfico 7. Respostas corretas dos alunos quanto a classificação dos animais de acordo com os critérios adotados pela IUCN

Fonte: As autoras.

Ainda nessa questão, outro animal que merece destaque é a onça pintada, em que apenas $8 \%$ dos alunos, tanto no questionário pré quanto no pós-atividade didática, acertaram que esta espécie se encontra em situação crítica, muito próxima de ser extinta. Esse resultado foi uma surpresa, uma vez que a onça pintada é um animal presente em todo território mato-grossense e, por isso, teoricamente deveriam saber mais informações sobre ela. O que,

\begin{tabular}{l|c|c|c|c|c|c} 
() Rev. Educ. Perspec. & Viçosa, $M G$ & v.8 & n.3 & p.496-517 & set./dez.2017 & eISSN 2178-8359 \\
\hline
\end{tabular}


consequentemente, levaria os alunos a discutirem sobre o assunto, ajudando e incentivando a preservação da espécie.

Esses resultados permitem inferir que talvez as escolas não incentivem ou não busquem informações sobre os animais de suas regiões, pois, geralmente, as mesmas seguem o livro didático fornecido pelo governo, que não foca em espécies de acordo com cada região e que leva muitas vezes os alunos a estudarem espécies de outros países deixando de conhecer as espécies de seu próprio país. O que pode ser observado no gráfico 8 , em que apenas três alunos acertaram a tática de sobrevivência da onça pintada, demonstrando que apesar de ser um animal de grande importância para a fauna do nosso país e do nosso estado, os alunos não detêm muitas informações sobre esse animal.

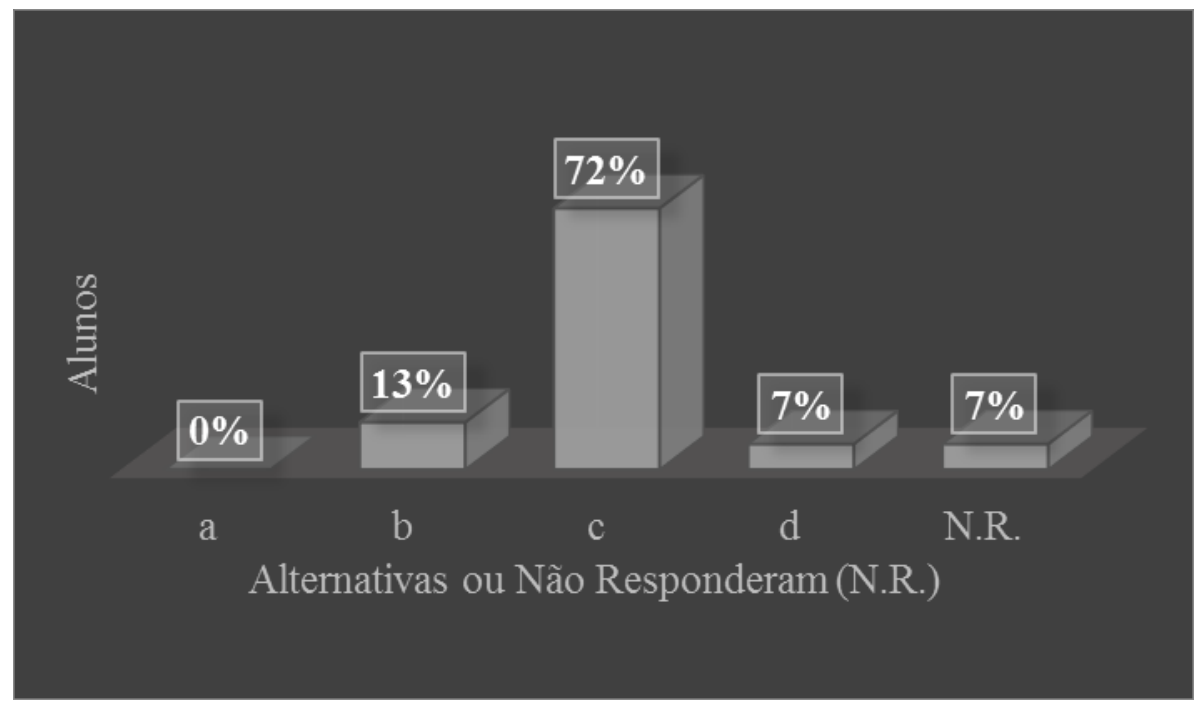

Gráfico 8. Respostas corretas dos alunos do ensino médio pré-jogo, quando questionados sobre as táticas de sobrevivência da Phantera onca conhecida popularmente como onça pintada e animal símbolo da fauna da região onde o questionário foi aplicado.

Fonte: As autoras.

Segundo Wortmann, Souza e Kindel (1997), na escola normalmente são apresentados aos alunos, nas aulas de Ciências, conteúdos sobre animais e vegetais que não são do ambiente dos mesmos, aparecendo fora do contexto que os estudantes vivem, dificultando ainda mais o aprendizado do alunado. Tavares (2013) reforça que a distância entre o que está sendo estudado e o dia a dia dos estudantes é uma das problemáticas do ensino de Ciências e Biologia, o que dificulta o aprendizado dos alunos, pois não há contato com o real para ilustrar o que estão aprendendo em sala.

Já em relação a quais animais estavam em risco de extinção, categorizado como LC (não ameaçada) de acordo com a IUCN, das alternativas propostas a maioria acertou, optando pela 


\section{RELATO DE EXPERIÊNCIA}

DOI: $10.22294 /$ eduper/ppge/ufv.v8i3.897

alternativa (a) como correta, 65\% dos alunos na pré-atividade e $80 \%$ na pós-atividade didática, como pode ser observado no gráfico 9. O que demonstra que apesar da defasagem da abordagem sobre o assunto nas escolas, os alunos possuem alguma informação sobre o risco em que certos animais se encontram.

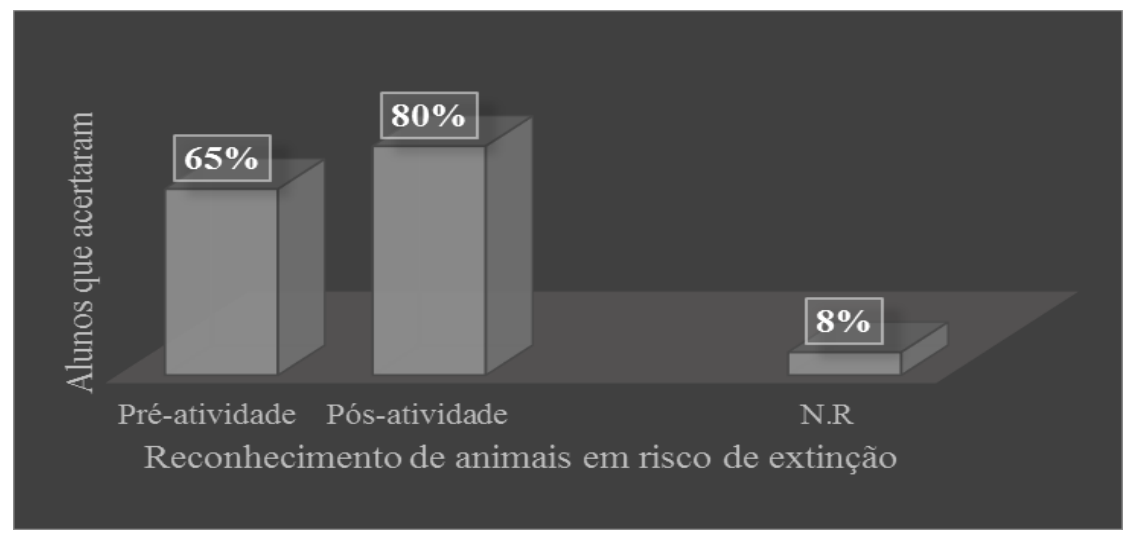

Gráfico 9. Reconhecimento da alternativa correta referente as espécies que não correm risco de extinção consideradas pela IUCN como não ameaçada (LC) pelos alunos do ensino médio no pré e pós-jogo. Fonte: As autoras.

Ao perguntar para os alunos sobre exemplos de animais que eles conheciam que estavam em risco de extinção, os mesmos mostraram que tinham conhecimento que alguns animais estavam em risco na natureza. No questionário pós-atividade didática houve um aumento expressivo de espécies citadas por eles e uma maior diversidade de animais em relação ao questionário pré-atividade, fato que demonstra a efetividade do jogo em proporcionar um maior conhecimento sobre o assunto. Alguns dos animais citados foram o lobo guará, arara azul, tubarão branco, onça pintada, mico-leão-dourado, bicho preguiça entre outros. Sendo que um dos animais mais citados foi a arara azul. Além dos que constavam no jogo também foram citados animais como o urso panda, boto cor-de-rosa e as abelhas.

Na questão que abordava sobre a opinião dos alunos em relação à funcionalidade do jogo, 89\% dos alunos responderam que o jogo "Animal Combate" funcionou como um instrumento de revisão e aplicação de conhecimento e quatro alunos responderam que não (Gráfico 10).

Dentre os que responderam positivamente, algumas justificativas foram:

\footnotetext{
"Sim, educativo, mas se tivéssemos mais tempo ia ser mais legal".

"Sim, muito educativo".

"Sim, ele ensina muito".

"Sim, me fez lembrar de muitos animais e ajudou no conhecimento de novos".

"Sim, pois as características mais importantes dos animais estão lá e fica mais fácil de aprender sobre eles".
} 


\section{RELATO DE EXPERIÊNCIA}

DOI: $10.22294 /$ eduper/ppge/ufv.v8i3.897

"Sim, pois continha informações como filo, tática de guerra, tempo de vida, prole, tamanho e peso e a alimentação dos animais".

"Sim, nos permitiu relembrar o que vimos desde o começo do ensino médio".

"Sim, pois percebi que desconhecia a maioria dos animais".

"Sim, me ajudou com a lista da IUCN".

"Sim, na verdade tem coisas que nem foi ensinado".

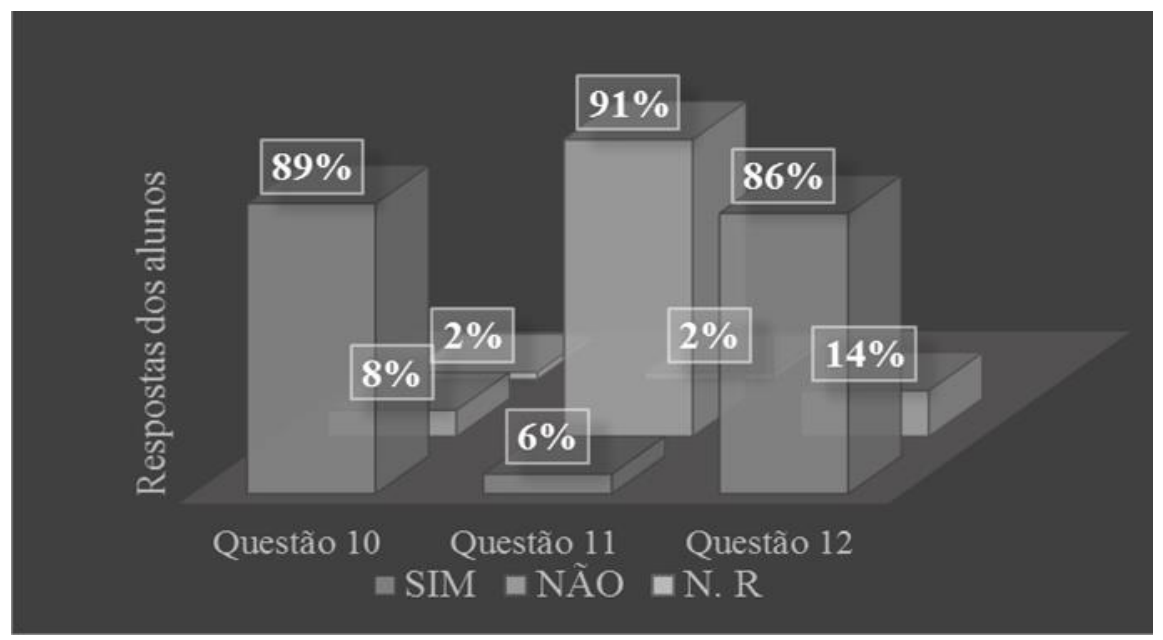

Gráfico 10. Opinião dos alunos do ensino médio em relação ao jogo "Animal Combate" referente se o jogo funcionou como instrumento de revisão e aplicação de conhecimento (Q10), se os mesmos gostaram ou não (Q11), e se tinham alguma sugestão (Q12).

Fonte: As autoras.

Nesta perspectiva, o jogo proposto, de forma divertida e prazerosa, mostrou-se adequado para o ano no qual foi aplicado, caracterizando-se como uma ferramenta complementar de ensino e aprendizagem (MIRANDA, 2001), podendo então ser utilizado como uma estratégia para melhorar o desempenho dos estudantes em conteúdos complexos como a zoologia e ecologia.

Tal fato, demonstra a importância de materiais didáticos como o jogo "Animal Combate" nas aulas de Biologia, principalmente, com conteúdos considerados difíceis de serem abordados como a zoologia e a ecologia, que incluem muitos temas ao mesmo tempo, auxiliando o professor a ministrar os conteúdos de uma forma mais interligada, possibilitando que os alunos interajam mais em sala.

Ao perguntarmos se eles tinham alguma sugestão para o jogo, $91 \%$ dos alunos disseram que não e dentre os que responderam positivamente, uma das sugestões foi " $a$ venda do produto $e$ distribuição nas escolas". Já quando perguntados se gostaram ou não do jogo "Animal Combate", $86 \%$ dos alunos disseram que sim (Gráfico 10), pois aprenderam várias coisas sobre os animais, além de se divertirem. Dentre as respostas estão:

"Sim, porque pode nos ensinar coisas sobre os animais em geral".

"Sim, bom porque além de se divertir serve para estudar alguns animais".

"Sim, é empolgante e gera sede de conhecimento".

(c) Rev. Educ. Perspec.

\begin{tabular}{l|c|c|c|} 
Viçosa, $M G$ & v.8 & n.3 & p.496-517
\end{tabular}

set./dez.2017




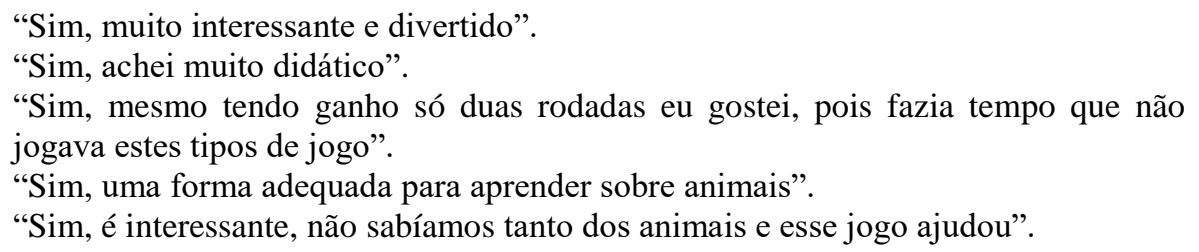

Para resgatar o interesse dos alunos em querer aprender é importante se utilizar de novas metodologias, pois, atualmente, diante de tantas tecnologias e das diferenças entre os alunos que compõem uma sala de aula, por muitas vezes o quadro, o giz e a saliva, não são mais suficientes (FIALHO, 2008), deixando os alunos cada vez mais desinteressados e distantes da educação.

Os alunos de um modo geral, levaram o jogo a sério, como uma disputa, deixando aparecer o sentimento competitivo e a vontade de ganhar. O que colabora com os resultados de Fialho (2008), em que ele diz que o fator competição é natural, e deve ser tratado com tranquilidade pelos professores, entretanto, os mesmos devem estar preparados, deixando claro que esse tipo de competição precisa ocorrer apenas no jogo.

Além do espírito de competição, o jogo didático proporciona aos alunos uma maior interação, permitindo que os mesmos percebam a presença de outros alunos, promovendo o respeito ao próximo e a detenção não só de conhecimento, mas de limites e regras (TEIXEIRA; ROCHA; SILVA, 2005). É de suma importância que haja relação entre o jogo e o conteúdo que o professor esteja lecionando naquele período em sala, pois só assim o uso de tal recurso faz sentido, facilitando a aprendizagem, de forma que envolva o professor e os alunos, sendo ambos inseridos no processo ensino-aprendizagem (FIALHO, 2008).

Outro fator relevante para que o professor utilize os jogos didáticos nas suas aulas é o tempo disponível que ele tem para aplicação dos mesmos, pois este pode interferir diretamente no processo de aprendizagem dos estudantes que participam da atividade. O que pode ser comprovado se analisarmos o gráfico 11, no qual se verifica que a turma do período vespertino teve uma média maior de acertos das questões propostas no questionário pósatividade do que as turmas dos outros dois períodos. 


\section{RELATO DE EXPERIÊNCIA}

DOI: $10.22294 /$ eduper/ppge/ufv.v8i3.897

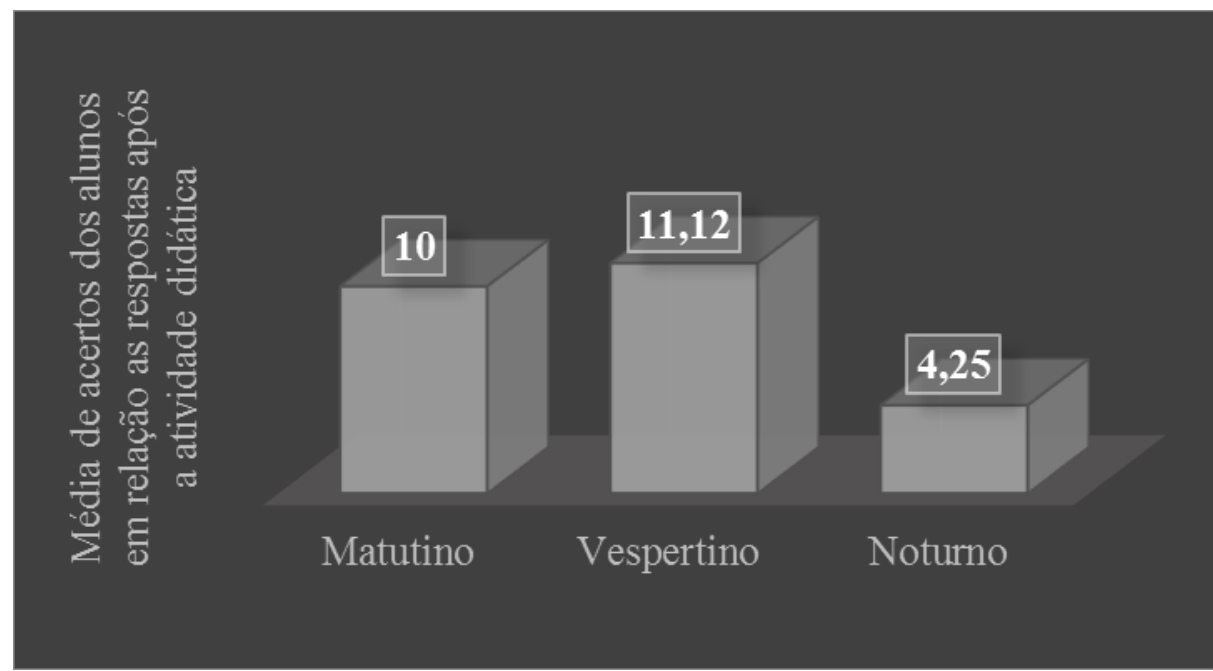

Gráfico 11. Média de acertos dos alunos em relação às respostas das questões propostas no questionário pós-atividade didática.

Fonte: As autoras.

As turmas do período matutino e noturno tiveram uma aula hora enquanto a turma do período vespertino teve duas horas aula para a realização da mesma atividade, conforme explicado na seção "Material e Métodos". Tal diferença de tempo para a atividade demonstra que o recurso didático necessita de maior tempo para melhores resultados.

Em termos gerais, o jogo teve um bom resultado, agradou aos alunos e mostrou que o conhecimento pode ser divertido, e, avaliando os questionários, podemos afirmar que o jogo foi um bom instrumento de ensino-aprendizagem.

Cabe reforçar que os jogos didáticos, assim como outros instrumentos de ensino, são uma ferramenta, um suporte para o professor e não a substituição do método que ele já traz consigo (ZANON; GUERREIRO; OLIVEIRA, 2008), contribuindo para o ensinoaprendizagem, pois, se o professor só se utilizar do livro deixará de falar sobre vários assuntos importantes para os alunos, tendo em vista que nos Parâmetros Curriculares Nacionais (BRASIL, 2000), é previsto que o estudo das Ciências Naturais deva incluir diferentes métodos ativos, como os jogos, uma vez que, um estudo exclusivamente livresco pode deixar enormes lacunas na formação dos estudantes.

Desta forma, os resultados expostos permitiram que fosse confirmada a ideia de que os jogos didáticos podem estimular a fixação, assimilação e construção de novos conhecimentos, colaborando com diversos estudos sobre a utilização de jogos didáticos na escola (MIRANDA, 2001; CAMPO et al., 2002; FIALHO, 2008; JORGE et al., 2009; PEDROSO, 2009). Tal ferramenta facilita o processo de ensino e aprendizagem dos alunos e favorece a construção de conhecimento dos mesmos com auxílio dos professores. 


\section{RELATO DE EXPERIÊNCIA}

DOI: 10.22294/eduper/ppge/ufv.v8i3.897

Assim, o jogo "Animal Combate" pode ser utilizado nas aulas de Ciências e/ou Biologia em conteúdos como: Sistema de classificação dos organismos; Nomenclatura zoológica; na ecologia (relações entre os seres vivos; cadeia trófica e teia alimentar); na reprodução dos animais; na biogeografia, sugerindo aos alunos que agrupem os animais das cartas por biomas; na Educação Ambiental e conservação, para conscientizar os alunos de quais animais estão ameaçados de extinção e discutir as possíveis soluções; na Evolução, abordando a especiação e adaptação dos animais ao ambiente; na Etologia, discutindo os diferentes comportamentos animais, entre outros.

Essas sugestões de conteúdos que podem ser trabalhados utilizando o jogo "Animal Combate', são dicas para os professores, os quais são livres para adaptar o jogo à necessidade da turma e aos temas ministrados em sua disciplina.

\section{CONSIDERAÇÕES FINAIS}

Durante e após a aplicação do jogo "Animal Combate" verificou-se que os alunos se mostraram satisfeitos e com maior compreensão dos conteúdos de zoologia e ecologia, participando ativamente da atividade didática, prevalecendo a empolgação e alegria em todas as três turmas de estudo.

A análise da aplicabilidade do jogo como um instrumento pedagógico, no ensino de Biologia, pode ser demonstrada a partir da avaliação dos questionários pré e pós-atividade didática, evidenciando-se um aumento dos acertos das respostas e mostrando-se eficaz como instrumento motivador da aprendizagem. Sendo que o tempo diferente entre as turmas, para a aplicação da atividade didática, interferiu na média de acertos, confirmando que o tempo é um fator importante para se atingir um melhor resultado no ensino e aprendizado dos alunos.

Pelo exposto, entende-se que o jogo deveria merecer um espaço e um tempo maior na prática pedagógica cotidiana dos professores, podendo, dessa forma, melhorar o ensinoaprendizagem dos alunos, não só em conteúdos extensos como a biologia, mas em todos os conteúdos da grade curricular do ensino fundamental e médio.

Por fim, o jogo "Animal Combate", como instrumento pedagógico, agradou os alunos e os levou a compreender e conhecer mais sobre os animais, pois como observado com tal experiência, os alunos possuem grandes dificuldades para entender os conteúdos envolvendo classificação e ecologia do Reino Animalia, evidenciando a necessidade de um ensino voltado para a realidade do aluno (fauna regional), além de uma deficiência nos conteúdos sobre conservação e extinção dos animais, em que o jogo proporcionou informações que, muitas vezes, não estão contidas nos livros didáticos.

\begin{tabular}{l|c|c|c|c|c|c|} 
(C) Rev. Educ. Perspec. & Viçosa, $M G$ & v.8 & n.3 & p.496-517 & set./dez.2017 & eISSN 2178-8359 \\
\hline
\end{tabular}




\section{REFERÊNCIAS}

AMORIM, Alessandra dos Santos. A influência do uso de jogos e modelos didáticos no ensino de biologia para alunos de ensino médio. 2013. Monografia (graduação) Universidade Estadual do Ceará, Centro de Ciências da Saúde, Curso de Ciências Biológicas a Distância, Beberibe, 2013.

ASSIS, Tânia Regina; COSTA, Fabiano Gonçalves; COSTA, Priscila Carosa; CASAGRANDE, Jéssica; CASTRO, Bruna Jamila. Contribuições de um jogo didático para o ensino de Zoologia nas aulas de Biologia. In: $3^{\mathbf{0}}$ Congresso Internacional de Educação Educação: Saberes para o século XXI, 2011.

BASTOS, Pedro de Souza Junior. Metodologia e estratégias para o ensino de zoologia. Distrito Federal, dez. 2013.

BRASIL. Parâmetros Curriculares Nacionais. Ensino Médio: orientações educacionais complementares aos Parâmetros Curriculares Nacionais - Bases Legais. Brasília: Ministério da Educação (MEC), Secretaria de Educação Média e Tecnológica (Semtec), 2000.

CAMPOS, Luciana Maria Lunardi; BORTOLOTO, Tânia Mara; FELICIO, Ana Karina. A produção de jogos didáticos para o ensino de Ciências e Biologia: uma proposta para favorecer a aprendizagem. Caderno dos Núcleos de Ensino, p. 35-48, 2003.

CASAS, Luana Lopez; AZEVEDO, Rosa Oliveira Marins; SOUZA, Carol Ferreira; CALADO, Nathércia Vasconcelos. Utilização de jogos como recurso didático para o estudo de embriologia. 2010.

DELIZOICO, Demétrio; ANGOTTI, Jose André. Metodologia do ensino de ciências. São Paulo; cortez, 1994.

FIALHO, Neusa Nogueira. Os jogos pedagógicos como ferramentas de ensino, 2008. Disponível em: 〈http://www.pucpr.br/eventos/educere/educere2008/anais/pdf/293_114.pdf〉. Acesso em: 20 dez. 2016.

GAGNÉ, Robert. Como se realiza a aprendizagem. Rio de Janeiro: Ao Livro Técnico, 1971.

JANN, Priscila Nowaski; LEITE, Maria de Fátima. Jogo do DNA: um instrumento pedagógico para o ensino de ciências e biologia. Ciências \& Cognição. v. 15, p. 282-293, 2010.

JORGE, Viviane Loureiro et al. Biologia limitada: um jogo interativo para alunos do terceiro ano do ensino médio. In: VII ENPEC: Encontro Nacional de Pesquisa em Educação em Ciências. Florianópolis, nov. 2009. 
MIRANDA, Simão. No Fascínio do jogo, a alegria de aprender. Ciência Hoje, São Paulo, v. 28 n. 168, p. 64-66, 2001.

NEVES, Ágata Laisa; SOUSA, Gardene Maria; ARRAIS, Maria das Graças Medina. A produção de jogos didáticos de botânica como facilitadores do ensino de ciências na EJA. SBEnBio, n. 7, out. 2014.

PAJOLA, Franciele et al. Recreação no Ensino de Ciências conhecendo a Tabela Periódica. In: IX Reunião Anual de Didática e Prática de Ensino, Catalão, p. 225-227, 2009.

PEDROSO, Carla Vargas. Jogos Didáticos no Ensino de Biologia: uma proposta metodológica baseada em módulo didático. In: IX Congresso Nacional de Educação Educere, III Encontro Sul Brasileiro de Psicopedagogia, 2009.

PINTO, Leandro Trindade. O uso de jogos didáticos no ensino de ciências no primeiro segmento do ensino fundamental da rede municipal pública de Duque de Caxias. 2009. Dissertação (Mestrado) - Instituto Federal de educação, Ciência e Tecnologia, Rio de Janeiro, 2009.

RODRIGUES, Marciel Elio; JUSTINA, Lordes Aparecida Dela; MEGLHIORATTI, Fernanda Aparecida. O Conteúdo de sistemática e Filogenética em livros didáticos do ensino médio, 2011.

SANTOS, Saulo Cézar Seiffert; TERÁN, Augusto Fachin. Possibilidades do uso de analogias e metáforas no processo de ensino-aprendizagem do ensino de zoologia no $7^{\circ}$ ano do ensino fundamental. In: VIII Congresso Norte Nordeste de Ensino de Ciências e Matemática. Boa Vista, 2009.

SILVA, Isayane Karinne de Oliveira; MORAIS, Marçal José de Oliveira. Desenvolvimento de jogos educacionais no apoio do processo de ensino-aprendizagem no ensino fundamental.

HOLOS, RN, ano 27, v. 5, 2011.

TAVARES, Priscila Carvalho. Utilização de jogo educativo como proposta para favorecer o ensino de ciências nas turmas do $8^{\circ}$ ano da Escola Municipal Maria Caproni de Oliveira, Município de Carvalhópolis MG, 2012. Dissertação (monografia) - Instituto Federal de Educação, Ciência e Tecnologia do Sul de Minas Gerais, Campus Machado, 2012.

TEIXEIRA, Mônica de Carvalho; ROCHA, Leandra Jacinto; SILVA, Vanessa Souza. Lúdico: Um Espaço para a Formação de Identidades. In: III Simpósio de Formação de Professores de Juiz de Fora, 2005.

WORTMANN, Maria Lucia Castagna; SOUZA, Nadia Geisa Souza; KINDEL, Eunice Aita Isaias. O estudo dos vertebrados na escola fundamental. São Leopoldo, RS: UNISINOS, 1997. 
ZANON, Dulcimeire Aparecida Volante; GUERREIRO, Manoel Augusto da Silva;

OLIVEIRA, Robson Caldas. Jogo didático Ludo Químico para o ensino de nomenclatura dos compostos orgânicos: projeto, produção, aplicação e avaliação. Ciências \& Cognição

(UFRJ), Rio de Janeiro, v. 13, p. 72-81, 2008.

\section{NOTAS}

\footnotetext{
${ }^{\text {i }}$ Para maiores informações sobre como o jogo foi elaborado pela equipe consultar: CALVO, Isabela de Almeida et al. Animal Combate: Um Novo Jogo para Auxiliar no Ensino de Zoologia no Ensino Fundamental e Médio. In: Anais Jornada Científica da UNEMAT, v. 7, Cáceres/MT, Brasil, dez. 2016. Disponível em: <https://goo.gl/YFrtn8>. Acesso em: 20 dez. 2017.
}

\section{Sobre os Autores}

Leandra de Amorim da Silva: Bióloga na Universidade do Estado de Mato Grosso campus de Tangará da Serra. E-mail: leamorim17@ @otmail.com - ORCID: http://orcid.org/00000003-4792-6284

Angélica Massarolli: Doutoranda do Programa de Pós-graduação em Zoologia da Universidade Federal do Paraná. E-mail: angelicamassaroli@gmail.com - ORCID: http://orcid.org/0000-0003-1914-5739

Alessandra Regina Butnariu: Curso de Ciências Biológicas Universidade do Estado de Mato Grosso campus de Tangará da Serra. E-mail: alebut@ unemat.br - ORCID: http://orcid.org/0000-0001-8682-3267 